\title{
Correlation Between the Heat Treatment Applied in the Processing of Meat Products and Listeria Monocytogenes
}

\author{
Adrian-Anton SĂLĂGIAN FLOREA ${ }^{1,2}$, Marian MIHAIU ${ }^{1}$ and Ioan PASCA ${ }^{1 *}$ \\ ${ }^{1}$ University of Agricultural Sciences and Veterinary Medicine, Faculty Of Veterinary Medicine, 3-5 \\ Manastur Street, 400372, Cluj-Napoca, Romania \\ ${ }^{2}$ Naposigal Quality S.R.L., 15 Viilor Street, 400347, Cluj-Napoca, Romania \\ *Corresponding author, e-mail: asalagian@gmail.com \\ Bulletin UASVM Veterinary Medicine 71(2) / 2014, \\ Print ISSN 1843-5270; Electronic ISSN 1843-5378 \\ DOI:10.15835/buasvmcn-vm: 10492
}

\begin{abstract}
The possible occurrence of Listeria monocytogenes in meat products is of great concern not only for the food safety authorities but also for processors and consumers. Considering the specific characteristics of the thermal processing, we can use these facts to validate the subsequent processes, regarding the recontamination of meat products with Listeria monocytogenes. The microbiology testing for the identification of Listeria monocytogenes was conducted at a meat processing facility in Cluj County by a third-party lab certified by the Romanian Accreditation Association-RENAR. The applied methodology complies with Regulation (EC) 2073/2005, and SR EN ISO 112901:2000/A1-2005. The monitoring of the thermal processing was performed daily on each batch of the end product, but for the study only the sampled batches were considered. The samples were collected from the end-product storage before the food products came from the immediate control of the operator within the sector that produced it. For two years (2012-2013) none of the samples tested positive for Listeria monocytogenes. The absence of Listeria monocytogenes in the tested samples proves, on one hand, the innocuousness of the sampled food products, and on the other hand, the compliance with all the regulations concerning hygiene and the good practices that excluded a possible recontamination of the meat products along the production line from the thermal processing to the endproduct storage, prior to the delivery.
\end{abstract}

Keywords: HACCP, heat treatment, Listeria monocytogene,meat products

\section{INTRODUCTION}

The heat treatment operates by destroying a considerable number of microorganisms and by improving the shelf life of products, provided that the products do not contaminate after this step (Boles, 2010). Among the pathogen microorganisms which can cause the food poisoning, a special attention is given to Listeria monocytogenes, due to its capacity to affect especially the persons with a deficient immunity system like children or pregnant women.

Data accumulated during the last three decades clearly demonstrate that Listeria spp. is a welldefined bacterium that possesses a number of features, distinguishing itself from the other Gram positive bacteria. It is not a coryneform bacterium as evidenced by a number of studies which evaluated the chemotaxonomic properties, and various rRNA and DNA sequencing characteristics. However, the exact phylogenetic position of this genus still remains controversial. Although it is generally agreed that its nearest neighbor is Brochothrix, its relationships with other members of the low G+ C percent DNA content Grampositive bacteria, especially with Lactobacillus, need further clarification (CE, 1999).

According to the standard legislation, the Regulation EC 2073/2005 amended with the Regulation 1441/2007 stipulates that all food products ready for consumption, susceptible for Listeria monocytogenes development, other than those destined for newborns or special medical 
diets, must be negative for this microorganism, if the samples are collected during the final storage and before they are marketed.

Recent studies show that, on a European level, in the year 2012, the number of contaminated cases with Campylobacter is in a slight decrease, the ones with Salmonella are maintain at the same levels, but unfortunately the listeriosis cases are continually growing, reaching a number of 1642 cases in 2012 (EFSA, 2014). On the other hand, from the available data of the RASFF (Rapid Alert System for Food and Feed), there are no products in Romania found positive for Listeria monocytogenes.

If we take into consideration the specific characteristics of the heat treatment and the microbiological examination of the end products, we can use these data to validate the processes that are developed afterwards, in what concerns the recontamination of the meat products with Listeria monocytogenes.

At the processing level, it is important to ensure that the processes are developed according to the plans and that they reach the purpose concerning the food safety. Thus, in regulation SR EN ISO 22000:2005 there is a clause regarding the validation of the combinations of control measures which implies the taken into consideration the preliminary operational programs and the HACCP plan.

\section{MATERIALS AND METHODS}

The study was performed on a number of meat products, such as ham, baloney, various kinds of sausages with particular physical-chemical characteristics (table 1). The samples were taken from a meat processing unit, found in Cluj county.

The microbiological examination:

The microbiological exams for the isolation and confirmation of Listeria monocytogenes were performed in an authorized food safety laboratory that has RENAR approval for performing such analyses. The method applied in this study is the one stipulated in the Regulation (EC) no. $1441 / 2007$, respectively SR EN ISO 112901:2000/A1-2005. Briefly, the protocol followed the enrichment steps in demi-Fraser broth (Oxoid, England), selective enrichment in Fraser broth (Oxoid, England), isolation on ALOA media and identification on PALCAM agar. Green colour colonies surrounded by a black area on PALCAM agar plates were collected for further confirmation (API tests) along with the reference strain $L$. monoytogenes type 1 ATCC 19111.

\section{Heat treatment analysis:}

The data analysis regarding the heat treatment was made automatically by using a calibrated probe with the help of a specialized software HI 98840 (Hanna Instruments, Germany). The monitoring of the heat treatment was performed for each lot of end product studied, daily but in this study we took into consideration only the lots from were samples were taken. The heat treatment cells used by the processors have the possibility of permanent monitoring of the obtained values during the heat processing, and the informations are saved on an electronic device for data storage.

Tab. 1. The physical and chemical characteristics of the meat products taken into analysis

\begin{tabular}{|c|c|c|c|c|c|c|c|}
\hline \multirow[b]{2}{*}{ Product } & \multicolumn{2}{|c|}{ Measures } & \multirow[b]{2}{*}{$\mathrm{U}, \%$} & \multirow{2}{*}{$\begin{array}{c}\mathrm{NO}_{2} \\
\mathrm{mg} / 100 \mathrm{~g} \\
\max .\end{array}$} & \multirow[b]{2}{*}{$\mathrm{NaCl}, \%$} & \multirow{2}{*}{$\begin{array}{c}\mathrm{NH}_{3} \\
\mathrm{mg} / 100 \\
\mathrm{~g}, \max .\end{array}$} & \multirow[b]{2}{*}{$\begin{array}{c}\text { Storage, } \\
{ }^{\circ} \mathrm{C}\end{array}$} \\
\hline & $\begin{array}{l}\text { Length, } \\
\text { mm }\end{array}$ & $\begin{array}{c}\text { Diameter, } \\
\mathrm{mm}\end{array}$ & & & & & \\
\hline Sunca & 400 & 130 & 78 & 10 & 3 & 30 & $+2 \ldots+5$ \\
\hline “Oltenesti”Sausages & 280 & 10 & 55 & 10 & 3 & 45 & $+10 \ldots+12$ \\
\hline Traditional Sausages & 180 & 30 & 57 & 10 & 2 & 45 & $+10 \ldots+12$ \\
\hline Pork baloney & 500 & 115 & 68 & 10 & 2 & 30 & $+2 \ldots+5$ \\
\hline Pork sausage & 180 & 32 & 56 & 10 & 3 & 45 & $+10 \ldots+12$ \\
\hline Pork cremwurst & 200 & 22 & 64 & 10 & 2 & 45 & $+2 \ldots+5$ \\
\hline Chicken brest salami & 400 & 40 & 65 & 10 & 3 & 30 & $+2 \ldots+5$ \\
\hline Chicken brest baloney & 500 & 115 & 70 & 10 & 2 & 30 & $+2 \ldots+5$ \\
\hline "Rose" sausage & 200 & 30 & 55 & 10 & 3 & 45 & $+10 \ldots+12$ \\
\hline Smoked bacon & - & - & 68 & 10 & 3 & 45 & $+2 \ldots+5$ \\
\hline
\end{tabular}


The values obtained during the heat treatment were registered with the help of a calibrated probe that had a precision of $0,1^{\circ} \mathrm{C}$. The temperatures are registered automatically at 1 minute time interval.

The statistical analyses of the values obtained were analyzed in Windows XP program, using the Origin 8.5 software and graphics.

\section{RESULTS AND DISCUSSIONS}

In table 1 are presented some features of the studied products, which influence the development way of the heat treatment, respectively the stability in time of the product. From fig. 1 it is revealed that the $130 \mathrm{~mm}$ in diameter of the ham leads to a duration of the heat treatment of approximately 4 hours, while in a smaller diameter product (ex.: sausage $-22 \mathrm{~mm}$ ) the heat treatment is reduced to approximately 1 hour.

In all the cases the length of the heat treatment is of minimum 10 minutes, and the maintaining temperature of minimum $70^{\circ} \mathrm{C}$.

The samples for the analysis of Listeria monocytogenes were taken from the storage of end products, before it leaves the control of the operator which has released it. For each sample, 5 representative lots, according to the lot size, were taken. In all 14 products taken into analysis, the samples proved to be negative for Listeria monocytogenes. In the same time, from the storage of end products, 6 sanitation tampons for Listeria monocytogenes were taken, also these proven to be negative.
Given the fact that this bacterium has a high virulence, the incidence in ready to eat meat products (RTE-MP) is considered an indicator of the poor hygiene practices and conditions in the processing unit. This is a great cause of concern not only for the regulatory agencies but also for the processors and consumers. The parameters established in the products analyzed showed physical and chemical characteristics that support the growth of L. monocytogenes (pH: 5.4, U \%: around 60, etc.). The majority of Listeria spp. identified in earlier studies in RTEMP is represented by L. innocua and L. welshimeri. These species of Listeria are not pathogen for humans, meaning that listeriosis does not occur but spoilage can happen sooner if the products are contaminated.

In other similar studies performed in other countries, Garrido et al. (2009) and Vitas et al. (2004) reported level of 8.5 and $10 \%$ incidence of L. monocytogenes in RTE-MP. Our findings do not support the other studies which mean that all the hygiene practices in the unit studied are respected accordingly. We have investigated the occurrence not only in the case of L. monocytogenes but also for other possible Listeria spp., and find only negative samples. Some studies made by Vitas et al. (2004) sustain that in RTE-MP the dominant specie of Listeria is L. innocua, other revealed that L. welshimeri is the most prevalent one (Garrido et al., 2009). We cannot support any of these ideas given the fact that we could not detect the presence of this bacteria in the RTE-MP investigated. It

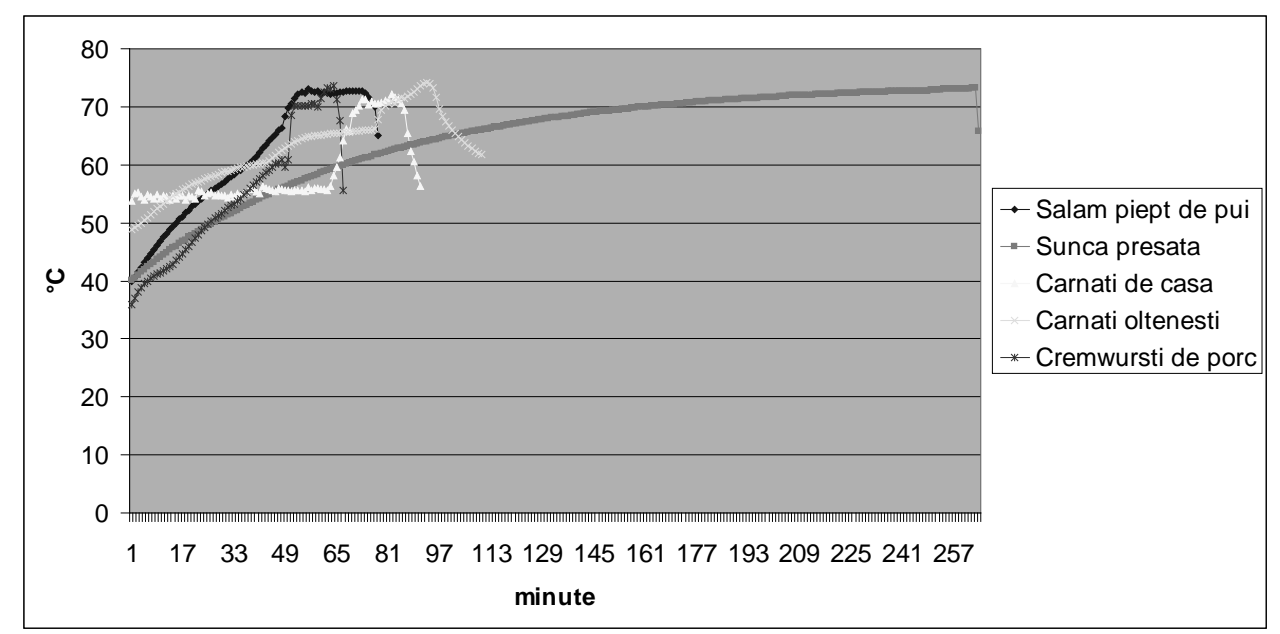

Fig. 1. The evolution of the temperature in time of some meat products 
seems that given the fact that RTE-MP is subjected to heat treatment during the processing, it is sufficient to kill L. monocytogenes possibly present in the raw materials. The occurrence of this bacterium is possible also by cross-contamination in the processing plant but our unit taken into study does not seem to have such problems.

The fact that our studied processing plant does not have positive sample is very insuring given the high number of possible contamination ways. It is a well-known fact that Listeria spp., including L. monocytogenes is widely distributed in nature and processing environments. The processing steps with the characteristic operations such as peeling, slicing, cutting, and packaging of heat treated meat have been reported to be critical control points of recontamination and transfer of Listeria monocytogenes. One of our objectives was also to quantify the contamination levels and estimate the actual threat for the consumer. Given the negative samples we can state that these heat processed products are safe for consumption, with the condition to strictly follow the hygiene practices and HACCP program.

Kushwaha et al. (2009) have suggested several ways to minimize the possible occurrence of this bacteria in RTE meat processing environments; regulation on the incoming raw meat to avoid it entering the facility, having sanitizing foot baths, sanitation of drains and air ducts, reduced use of high pressure water hoses during shifts, designing of instruments with minimal crevices for bacterial protection, sloped surfaces to avoid stagnant water collection, prevention of personnel flow from raw to post processing areas without appropriate sanitation and segregating drainage systems for raw and post processing areas (Snehal et al. 2014).

The specific measures can be considered efficient only when the hygiene requirements and the permanent monitoring of the RTE-MP are strictly followed.

\section{CONCLUSION}

The lack of Listeria monocytogenes in the analyzed samples, reveal on one hand the good processing and high level of hygiene in the unit studied. The heat treatments performed on the ready to eat meat products have probably inactivated the possible Listeria spp. bacteria in the raw material. We can safely state that the products studied are safe for public consumption and the level of human contamination with Listeria monocytogenes through RTE-MP is low.

\section{REFERENCES}

1. *** Commission Regulation (EC) No $1441 / 2007$ of 5 December 2007 amending Regulation (EC) No 2073/2005 on microbiological criteria for foodstuffs.

2. Boles JA (2010). Thermal processing. In Handbook of Meat Processing, edited by Fidel Toldra, Blackwell Publishing, Ames, Iowa, USA.

3. EFSA (Food Safety Authority, European Centre for Disease Prevention and Control) (2014). The European Union Summary Report on Trends and Sources of Zoonoses, Zoonotic Agents and Food-borne Outbreaks in 2012. EFSA Journal 2014;12(2):3547, 312 pp. DOI:10.2903/j. efsa.2014.3547

4. Garrido V, Vitas AI, Garcia-Jalon EI (2009). Survey of Listeria monocytogenes in ready-to eat products: prevalence by brands and retail establishments for exposure assessment of listeriosis in Northern Spain. Food Control. DOI: 10.1016/j.foodcont.2008.11.013

5. Snehal J, Gulati V, Bhave M and Palombo EA (2014). Prevalence and control of Listeria monocytogenes in food processing environments. In Listeria monocytogenes. Food sources, prevalence and management strategies edited by Edmund C. Hambrick, Nova Science Publishers, Inc., New York, USA.

6. Rocourt J, Buchrieser C (2007). The Genus Listeria and Listeria monocytogenes: Phylogenetic Position, Taxonomy, and Identification. In Listeria, listeriosis, and food safety, 3rd ed, edited by Elliot T. Ryser and Elmer H. Marth., CRC Press, Boca Raton, FL, USA.

7. Vitas AI, Aguado V, Garcia-Jalon EI (2004). Occurrence of Listeria monocytogenes in fresh and processed foods in Navarra (Spain). Int. J. Food Microbiol. 90:349-356.

8. http://ec.europa.eu/food/safety/rasff/portal/index_ en.htm. 